\title{
Statistical analysis of the distribution of infralittoral Cystoseira populations on pristine coasts of four Tyrrhenian islands: Proposed adjustment to the CARLIT index
}

\author{
Giovanna Jona Lasinio ${ }^{a}{ }^{*}$, Maria Alessandra Tullio ${ }^{a}$, Daniele Ventura ${ }^{b}$, \\ Giandomenico Ardizzone ${ }^{\mathrm{b}}$, Nadia Abdelahad ${ }^{\mathrm{b}}$ \\ a Department of Statistical Sciences, Sapienza University of Rome, P.le Aldo Moro 5, 00185, Italy \\ ${ }^{\mathrm{b}}$ Department of Environmental Biology, Sapienza University of Rome, P.le Aldo Moro 5, 00185, Italy
}

\section{A R T I C L E I N F O}

\section{Article history:}

Received 2 May 2016

Received in revised form

20 September 2016

Accepted 21 September 2016

Available online 4 October 2016

\section{Keywords:}

Cyptoseira amentacea

CARLIT

Auto logistic model

Poisson regression

Pontine islands

Giglio island

Tyrrhenian sea

Italian coasts

\begin{abstract}
A B S T R A C T
The influence of geomorphological features on the distribution of Cystoseira populations along the coasts of four pristine islands in the Tyrrhenian Sea (Italy, central Mediterranean) was studied by means of a model-based statistical analysis. The most relevant trait that determined the presence of these populations was found to be the coastline slope at the level of the infralittoral fringe. Our findings indicate that slopes above $60^{\circ}$ reduce the likelihood of Cystoseira communities. The effects of the coastline slope on the CARLIT index are considered and discussed in view of these findings. Pending further studies on the implementation of the CARLIT index in the Mediterranean basin, we suggest that any changes to the procedure or the hasty multiplication of reference sites be avoided, and instead propose a simple empirical adjustment of the EQ values to be able to more accurately monitor coasts with steep slopes using this index.
\end{abstract}

(c) 2016 Elsevier Ltd. All rights reserved.

\section{Introduction}

Cystoseira amentacea (C. Agardh) Bory (Phaeophyceae) is a brown alga that forms dense and continuous populations on upper infralittoral pristine rocky shores of the Mediterranean Sea (Ballesteros et al., 2007). The CARLIT (Cartography of littoral rocky shore communities) index, a EU Water Framework Directive (2000/60/CE) monitoring method developed and first applied to the Mediterranean coasts of Spain, assigned to Cystoseira amentacea, as well as to almost all other surface Cystoseira species, a high bio-indication sensitivity level (Ballesteros et al., 2007; Table 1). As C. compressa (Ballesteros et al., 2007; see also Thibaut et al., 2005) and, more recently, C. barbata (Nikolić et al., 2013) have also been observed in slightly more polluted waters, the protocol assigned a lower bio-indication sensitivity level to these species

\footnotetext{
* Corresponding author.

E-mail addresses: giovanna.jonalasinio@uniroma1.it (G. Jona Lasinio), daniele.ventura@uniroma1.it (D. Ventura),giandomenico.ardizzone@uniroma1.it (G. Ardizzone), nadia.abdelahad@uniroma1.it (N. Abdelahad).
}

when present without other Cystoseira species. Therefore, according to the CARLIT index, the Mediterranean algal communities of the upper infralittoral zone dominated by Cystoseira species, as well as the build-ups (trottoirs) of Lithophyllum byssoides (Lamarck) Foslie, indicate undisturbed environments, those dominated by Dictyotales and geniculate or crustose Corallinales indicate slightly polluted environments, and those dominated by Ulva, Cladophora and Cyanobacteria indicate extremely polluted environments (Ballesteros et al., 2007; see also Arevalo et al., 2007; Pinedo et al., 2007; Mangialajo et al., 2008a). To date, the CARLIT index has been applied in Spain (Ballesteros et al., 2007; Bermejo et al., 2013, 2014; Cavallo et al., 2016; Torras et al., 2016), Italy (Mangialajo et al., 2007; Asnaghi et al., 2009; Guala et al., 2010; Sfriso and Facca, 2011; the present paper), France, Malta (Blanfuné et al., 2011, 2017, already available on http:/dx.doi.org/10.1016/j.ecolind.2016.07.049), Croatia (Nikolić et al., 2013) and Albania (Blanfuné et al., 2016).

Since the distribution of the upper infralittoral macroalgal communities is affected not only by water quality but also by the coastline geomorphology, multivariate analyses have previously been applied (Ballesteros et al., 2007; Nikolić et al., 2013) to six categories of coastline (morphology, substrate constitution, slope, 
Table 1

Variable legend.

\begin{tabular}{|c|c|c|c|}
\hline Name of variable & Description & Type & Categories/units \\
\hline Aspect & Orientation of the coast & qualitative & $\begin{array}{l}\text { East (E), North (N), North-East (NE), North-West (NW), } \\
\text { South (S), South-East (SE), South-West (SW), West (W) }\end{array}$ \\
\hline Elevation & Elevation of the coast & quantitative & Continuous (meters) \\
\hline Landform & Morphology of the coast & qualitative & $\begin{array}{l}\text { Metric Block (MB), Low Cliff (LC), High Cliff (HC), Beach (B), } \\
\text { Other }\end{array}$ \\
\hline Coast Slope & Slope of the coast & quantitative & Degrees (circular) \\
\hline Coastline slope & $\begin{array}{l}\text { Slope of the coastline at the } \\
\text { infralittoral fringe }\end{array}$ & qualitative & $\begin{array}{l}\text { Low Slope }\left[0^{\circ}-30^{\circ}\right](\mathrm{LS}), \text { Medium Slope }\left[30^{\circ}-60^{\circ}\right](\mathrm{MS}) \text {, } \\
\text { High Slope }\left[60^{\circ}-90^{\circ}\right](\mathrm{HS})\end{array}$ \\
\hline $\begin{array}{l}\text { Sum of Neighbors } \\
\text { (SN) }\end{array}$ & $\begin{array}{l}\text { Number of occurrences in neighboring } \\
\text { sites as a proxy of spatial association } \\
\text { information }\end{array}$ & quantitative & Counts \\
\hline Cystoseira & $\begin{array}{l}\text { Presence and absence of Cystoseira } \\
\text { belts }\end{array}$ & binary & $0 / 1$ \\
\hline
\end{tabular}

orientation, type, i.e. natural or artificial, and wave exposure) to identify the geomorphological factors that most influence the distribution of these communities. The analyses revealed that the coastal morphology (i.e. the type of coast: high, low or composed of metric or decametric blocks), the natural or artificial type of substrate (Ballesteros et al., 2007), as well as the coastal morphology and the coastline slope (Nikolić et al., 2013) were the most relevant variables involved in determining algal distribution.

The importance of the role played by the coastline slope in the establishment of Cystoseira populations on pristine coasts first emerged in 2010, when the CARLIT index was applied by our group to the whole coastline of the Pontine islands (Ponza, Palmarola, Zannone, Ventotene, S. Stefano), which comprise the most pristine areas in the Lazio region (central Italy) and include two islands designated Marine Protected Areas (Ventotene and Zannone). The ecological status assigned by the CARLIT index to the coasts of these islands was moderate to good, which is in contrast to the high status assigned by the regional monitoring agency (ARPA Lazio) on the basis of physical-chemical data. The lower status assigned by the CARLIT index was particularly evident on Palmarola, an uninhabited island a long way from any anthropic impacts, where the ecological status was defined as "moderate", even though a trottoir of Lithophyllum byssoides was found on one rock, known as the Faraglioni di Mezzogiorno, that lies off the island. In order to understand why the CARLIT index did not yield the results that were expected for the Pontine islands, we analyzed the relationship between the presence of upper infralittoral Cystoseira spp. and the geomorphological features along the coasts of the Zannone by means of statistical models. The study, presented at a conference (Jona Lasinio et al., 2011), revealed that the steepness of the coastline appears to play a fundamental role in correctly predicting the presence of Cystoseira on the coastline. When the CARLIT index was subsequently applied to the coasts of the Island of Giglio (another pristine island in the central Mediterranean Sea in the Tuscany region), it worked perfectly, revealing a high ecological status of the coastal waters. The statistical analyses that had previously been applied to the Zannone were applied to Giglio and to the two Pontine islands of Ponza and Ventotene in order to further confirm the relationship between the presence of Cystoseira species and the geomorphological characteristics of these islands. The results of these studies are presented and discussed in the present paper.

A substantial innovation in this study is the use of a statistically rigorous approach that assesses (and hence accounts for) the uncertainty surrounding the quantification of biological indicators. The relationship between bio-indicators and environmental features (e.g. algal population and geomorphological factors) is commonly assessed by means of multivariate analyses, such as principal component analysis, multidimensional scaling or other descriptive tools that do not shed light on the statistical significance of findings, i.e. no uncertainty evaluation is undertaken when these relationships are described in this type of analysis. A protocol that includes simple statistical models that take into account every feature was used in this study to identify which attributes of the landscape significantly affect the presence/absence of Cystoseira belts along the coastline. This model-based approach can be used to define and rigorously infer relationships between features, thereby accounting for the uncertainty naturally associated with bio-indicator evaluations.

\section{Material and methods}

\subsection{Study area and field data}

The study was carried out along the upper infralittoral rocky shore in two sites in the central Mediterranean Sea (Tyrrhenian Sea): the Pontine Islands (40.907 N, $12.953 \mathrm{E})$, an archipelago encompassing five islands (Ponza, Zannone, Palmarola, Ventotene, Santo Stefano) and the Island of Giglio (42.352 N, $10.901 \mathrm{E}$ ). The study area is shown in Fig. 1, which highlights the islands' positions in relation to the Italian coast. The coasts of Ventotene, Ponza and Zannone were monitored in spring in 2009 and 2010 while those of Giglio were monitored in summer in 2012 and in autumn in 2014 by means of the CARLIT index (Ballesteros et al., 2007; Mangialajo et al., 2008b). The survey included the entire perimeter of the coastline of each island, with the exclusion of beaches and harbors as well as the sector of the coast of Giglio where the cruise ship Costa Concordia ran aground in January 2012 (the coastal sectors excluded are indicated as Other in Fig. 3 ). The islands' coastlines were surveyed using an inflatable boat, which was guided as closely as possible to the shore to record the length of each homogeneous sector of the coast as regards both the upper-infralittoral algal communities and the geomorphological factors, and thus build a field database. The field database was then used to build an integrated database by combining and calibrating the geomorphological features on the basis of a digital elevation model (DEM) which was, in turn, used for modeling purposes (see below). The following variables were considered in this study: (1) population type, (2) coastal morphology (landform) [high cliffs (HC), low cliffs (LC), metric blocks (MB), others/beaches (B)], (3) length (in meters) of the homogenous coastal sectors, (4) elevation, (5) coastline slope at the infralittoral fringe [three categories: low (horizontal slope, $0^{\circ}-30^{\circ}$ ), medium (sub-vertical slope, $30^{\circ}-60^{\circ}$ ) and high (vertical slope, $60^{\circ}-90^{\circ}$ )] and (6) aspect (orientation) of the coastline. Differences in the geology of the substrate between Giglio (prevalently granitic) and the Pontine islands (prevalently volcanic) were not taken into account in this study as the substrate constitution was not found to be a highly relevant geomorphological feature in determining alga distribution by either Ballesteros et al. (2007) or Nikolić et al. (2013). The values observed were then transferred into georeferenced maps of the islands and the ecological value (EQV) of 


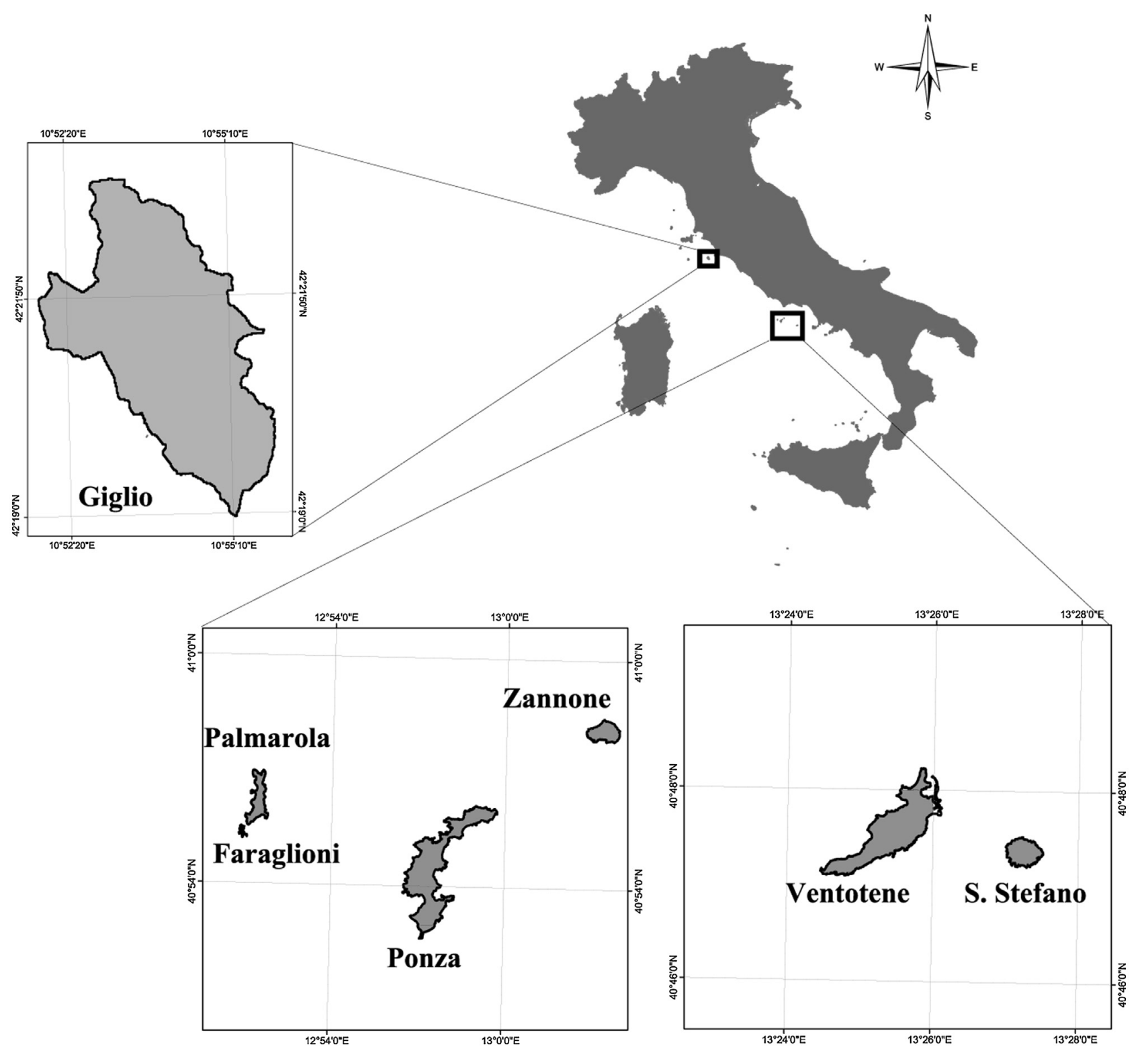

Fig. 1. Study area locations in relation to the Italian coastline.

each island was calculated according to the reference values proposed by Ballesteros et al. (2007) for the three geomorphological categories (high cliffs, low cliffs and metric blocks).

\section{Digital elevation model evaluation of geomorphological features}

The latest GIS and statistical models were used to assess, integrate and validate the features observed. Elevation, slope and aspect of the coastline measured in situ were verified and calibrated using the following ArcGIS 10.1 (ESRI, 2011) workflow: (a) importing a polyline shapefile representing the stretch of coast in which each measured variable were added in the attribute table; (b) importing of a digital elevation model ( $10 \mathrm{~m}$ cell size) provided by TINITALY as a raster dataset (Tarquini et al., 2007, 2012); (c) identification and production of raster maps representing the slope (i.e. gradient, or rate of maximum change in $z$-value from each cell of the raster surface), aspect (i.e. downslope direction of the maximum rate of change in value from each cell to its neighbors) and elevation; (d) creation of a regular grid of square cells $(10 \times 10 \mathrm{~m})$ overlapping the starting polyline shapefile; (e) implementation of zonal statistical tools in order to calculate common statistics such as mean, SD, median, minimum and maximum values of raster maps within the zones (i.e. square grid cells), and the compilation of these results in a table; (f) joining and relating the values calculated within each grid cell with the original polyline shapefile. A value of 1 (presence) or 0 (absence) in each DEM grid cell was associated with the presence or absence of Cystoseira species or other algal communities in any location falling within the cell. Unsurveyed areas, such as beaches and harbors, were directly assigned a value of 0 . The final set of variables is reported in Table 1 together with a brief description of the variables. Owing to limitations in the DEM resolution $(10 \mathrm{~m})$, small islands such as Santo Stefano and Palmarola may be represented with a very large approximation; neither island was consequently included in the inferential analysis.

\section{Statistical analysis}

In this study, the presence of the Cystoseira species on the upper infralittoral fringes of the Pontine islands and Giglio is related 
to geomorphological features (aligning recorded presence/absence with the aforementioned DEM). The observational unit is the $10 \times 10 \mathrm{~m}$ DEM grid cell. Simple logistic models are usually adopted to describe and predict dichotomous variables. However, it should be borne in mind that the presence/absence of plants and animals in any environment is naturally affected by spatial dependence, a characteristic not accounted for in simple logistic regression models. In this study, spatial dependence between observations is accounted for by using an autologistic model (Besag, 1975; Cressie, 2015; Fu et al., 2013). Although these types of model (automodels, Besag, 1975) have long been used in spatial statistics, they are rarely adopted in biological and ecological studies. One reason for which they are not adopted in ecological studies is that such models require a complete knowledge of the response variable, i.e. when dealing with presence absence data, both presences and absences must be recorded, and this is rarely done in studies on nature. However, in the present study, data were collected along the entire coast of each island and include all the recordable presences and absences. The data collected can thus be represented as an autologistic model. These models may be estimated by means of several approaches (Besag, 1975; Cressie, 2015), the simplest being the Pseudo-Likelihood maximization approach. This technique (Cressie, 2015 and references therein) reduces the autologistic model to a simple logistic regression between the presence/absence variable, with the external features adding an additional explanatory variable obtained by summing the response variable over a given set of neighboring sites (i.e. the number of occurrences in neighboring sites). This study adopted a socalled first order neighbor structure along the coastline, according to which adjacent DEM cells are considered neighbors. All other geomorphological features are considered explanatory variables. Model selection was performed using AIC, goodness of fit was measured as the percentage of explained deviance, and the predictive capacity of the model was measured according to the number of wrongly classified units (the fewer, the better). The following procedure was applied: (a) compute the model estimated probability of occurrence at each site, (b) if this probability is higher than 0.5 , associate 1 (presence) with the location, and 0 otherwise, (c) tabulate the values predicted in this way with the observed values and count how many locations out of the total number are wrongly classified.

To gain a further insight into the distribution of Cystoseira, the size of algae patches (described by the sum of neighbors) was correlated with geomorphological features using a Poisson regression (Cameron and Trivedi, 2013). The percentage of explained deviance was once again used to assess the models' goodness of fit and their predictive ability was evaluated by calculating the proportion of wrongly classified units, which was this time obtained directly from the predicted values of the models. A schematic representation of the statistical protocol adopted in the study is presented in Fig. 2.

\section{Results}

\subsection{Exploratory data analysis}

The coasts of the four islands considered in this study display a high level of morphological heterogeneity, though the prevalence of high cliffs places them within the high coast category. Giglio has a coastline slope at the infralittoral fringe that largely ranges from horizontal $\left(0^{\circ}-30^{\circ}\right)$ to sub-vertical $\left(30^{\circ}-60^{\circ}\right)(\mathrm{LS}+\mathrm{MS}=72.7 \%)$ (Fig. 3b). Cystoseira populations were dominant (74\%) on these coasts, with continuous belts or abundant patches accounting for $48 \%$ of the populations (Fig. 3a). Cystoseira amentacea var. stricta was the prevailing species in these populations. A limited num-
Table 2

Ecological values (EQV) for the 3 categories of coast (high, low and metric blocks) calculated on the Pontine islands and in the reference sites (Ballesteros et al., 2007).

\begin{tabular}{llll}
\hline & EQV (HC) & EQV (LC) & EQV (MB) \\
\hline Zannone & 7.75 & 9.95 & 7.40 \\
Ponza & 8.10 & 10.40 & 7.38 \\
Ventotene & 7.14 & 8.86 & 10.10 \\
References sites (Ballesteros et al., 2007) & 15.30 & 16.60 & 12.20 \\
\hline
\end{tabular}

ber of coralline communities were found (9\%). The CARLIT index assigned a high ecological status to Giglio.

On the Islands of Ventotene and Ponza, the percentage of horizontal to sub-vertical coastline slope (LS + MS) is still high, though lower than that found on Giglio (52.87\% on Ventotene and $43.9 \%$ on Ponza) (Fig. 3b). The largest presence of Cystoseira in the Pontine islands was observed on these two islands (47\% on Ventotene and $33 \%$ on Ponza). The percentage of Cystoseira belts on Zannone was relatively small (24\%), with the populations of $C$. amentacea never forming continuous belts but only relatively abundant patches. This island has the highest percentage of vertical coastline slope ( $\mathrm{HS}=60^{\circ}-90^{\circ}=70.3 \%$ ) and a percentage of metric blocks ( $\mathrm{MB}=54 \%$ ) that is more than twice as much as that found on the other islands (Fig. 3b). On the Pontine islands, Cystoseira amentacea var. stricta was accompanied by $C$. compressa, which was present in an even greater proportion. On Ventotene, shallow rocky pools were found to host small populations of Cystoseira species that displayed a high level of sensitivity (20), such as C. foeniculacea f. tenuiramosa, $C$. barbata and $C$. crinita. On all the Pontine islands, Corallinales were present in large amounts at the edge of vertical high cliffs and were found to be the dominant communities at Zannone. Worthy of note are the sunny low rocks completely covered by Cystoseria species that were found lying opposite high vertical cliffs lined by Corallinales on several occasions during the surveys. The ecological values calculated for the three categories of coast (high, low and metric blocks) on the Pontine islands were significantly lower than those reported by Ballesteros et al. (2007) in the reference sites (Table 2). The CARLIT index consequently yielded a good (Ventotene and Ponza) and moderate (Zannone) ecological status, whereas the regional physical-chemical water monitoring of these islands yielded a high ecological status for the years in which the survey was conducted.

\subsection{Modeling results}

Following the findings in the exploratory analysis, possible correlations between Cystoseira populations and the most relevant geomorphological characteristics according to Ballesteros et al. (2007) were investigated. A pairwise variable analysis was first performed by means of several chi square tests. Significant associations were found for all pairs. To verify the hypothesized relevance of the environmental factors, including those not considered in the CARLIT index, the autologistic, logistic and Poisson models were estimated. Table 3 summarizes the estimation results of the autologistic models. A bullet marks the significance (5\% error) of the explanatory variables in the final model.

The results of the simple logistic models are not reported in order to reduce the number of tables and graphs. A comparison between the logistic and autologistic models in terms of both explained deviance and prediction error highlighted the improvement yielded by the autologistic models (about 50\% more deviance explained and a reduction from approx. $15 \%$ in the prediction errors to $5 \%$ or less). In all the situations considered, both the spatial structure represented by the sum of the neighbors and the coastline slope were found to be significant, while the coastal morphology (Landform) was significant for Zannone and Ventotene alone. 


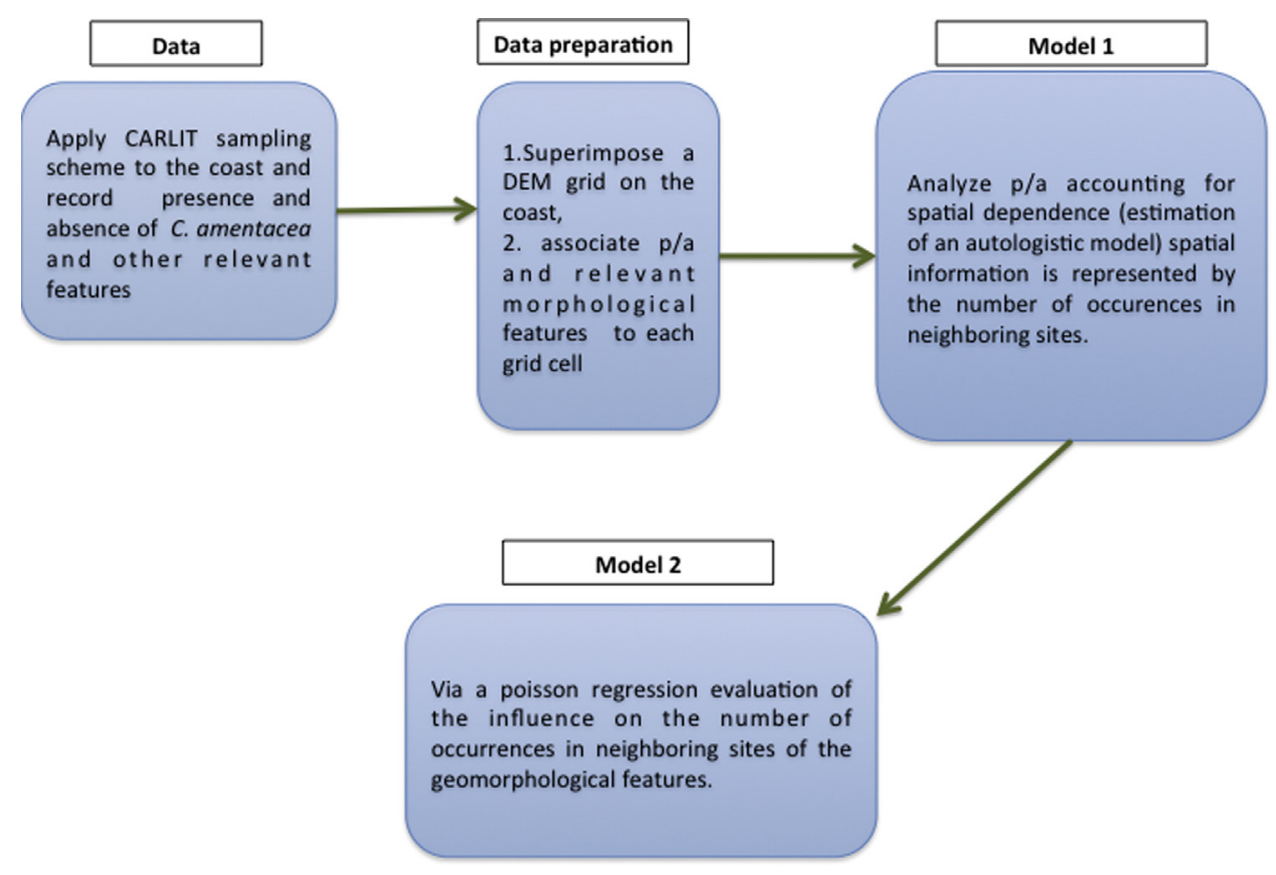

Fig. 2. Schematic representation of the statistical protocol.

Table 3

Autologistic Models estimated using maximum pseudo-likelihood - significant variables (5\% error), percentage of deviance explained and predictive error.

\begin{tabular}{|c|c|c|c|c|c|c|c|c|}
\hline Island & Sum of Neighbors & Aspect & Coast elevation & Landform & Coast slope & Coastline slope & \% Explained Dev. & Predictive Error \\
\hline Zannone & • & & & • & & • & 81.06 & 0.034 \\
\hline Ponza & $\bullet$ & & & & & $\bullet$ & 85.55 & 0.035 \\
\hline Ventotene & $\bullet$ & & & $\bullet$ & & $\bullet$ & 92.86 & 0.013 \\
\hline Giglio & $\bullet$ & & & & & • & 92.83 & 0.024 \\
\hline
\end{tabular}

Figs. 4 and 5 show the estimated coefficients and effects of the two variables together with their 95\% (Fig. 4) and 90\% (Figs. 5 and 6) confidence intervals.

The coefficients of the sum of neighbors in Fig. 4 point to the strong relationship between the likelihood of the presence of Cystoseira and the size of the belts. The larger the patches, the higher the probability of their presence given all the other information. The models' output highlights a clear separation between Giglio and the Pontine islands, which is in keeping with the marked differences in their morphological characteristics. In order to highlight the effects of the coastline slope categories in Fig. 5, the category high slope (HS) was considered as the corner point and the effects of all the other categories are highlighted using the latter as a reference $(0)$ point. The combination of landform and coastline slope, whose effects are shown in Fig. 6, was significant for Zannone and Ventotene (see Table 3). A one category combination, which in this case was the landform "High Cliff" and HS, was again considered as a reference point. In other words, plots revealed that the increasing values of neighboring occurrences (larger algae clusters) contribute to a growing probability of finding both Cystoseira and a more even slope. Coastline slope combined with landform at Ventotene and Zannone lent further support to this finding. A coastline slope of less than $60^{\circ}$ is associated with a higher probability of the presence of Cystoseira whenever the coastal morphology allows the alga to grow (hence excluding beaches and harbors).

The results of the analysis show that the influence of almost all the other factors vanishes when spatial structure, represented by the sum of the neighbors, was added to the model. The role of spatial relations, i.e. the size of spatial clusters, was therefore investigated. A Poisson regression analysis on the number of occurrences in neighboring sites and the geomorphological features in these sites has been performed. The results of this analysis are summarized in Table 4 using the same rationale as that adopted for the autologistic model summary. The Poisson regression only explained a portion of the Cystoseira cluster variation in the area, with an explained deviance ranging from $58.7 \%$ to $20.16 \%$ and a prediction error never below $26 \%$. The noteworthy finding was that the role of coastline steepness emerged as a fundamental factor in the increase in cluster size on all islands, followed by coast orientation (aspect) and landform. The influence exerted by coast slope on cluster size was less marked, it being significant for the Ventotene model alone. The combined effect of coastline steepness and landform exerts the strongest influence on the alga clusters, and indicates that whenever the coastline slope is high, regardless of the landform recorded, its effect is strongly negative (not shown and available from authors upon request).

\subsection{Discussion and concluding remarks}

On the Pontine islands, the high proportion of communities dominated by species with lower bio-indication values than those yielded by Cystoseira populations (i.e. geniculate or encrusting Corallinales, with respective values of 8 and 6 , see Ballesteros et al., 2007; Table 1) reduces the ecological status assigned to these coasts by means of the CARLIT index. This low status is not, however, due to a low water quality, as demonstrated by the fact that they were assigned a "high" ecological status by the physical-chemical regional monitoring agency. A key role on these islands appears to be played by the morphology of the coastline, which is more suited to the establishment of sciaphilous species, such as Corallinales, than to that of species requiring more sunlight. This point is supported by the observation, in several sites on these islands, 


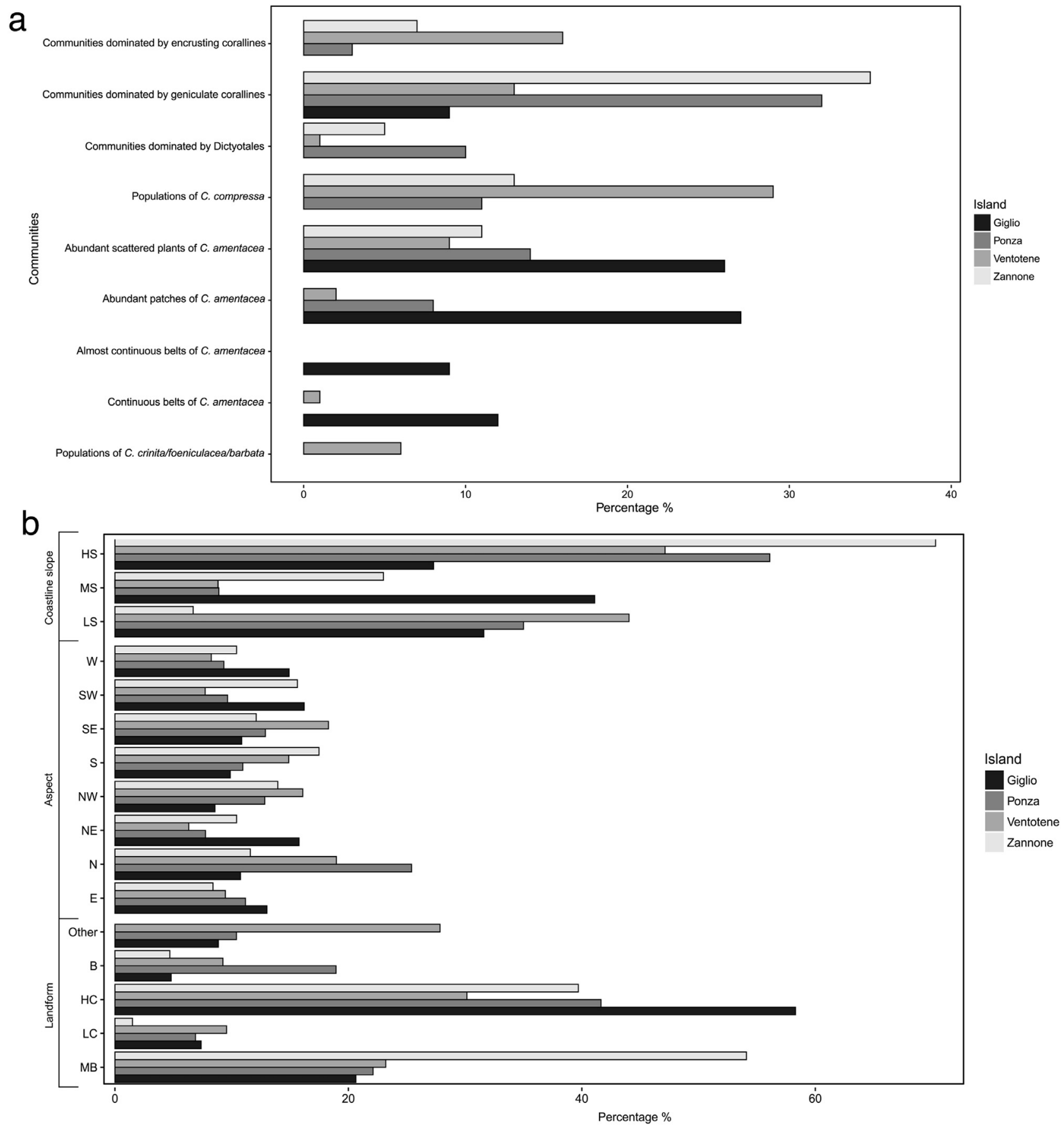

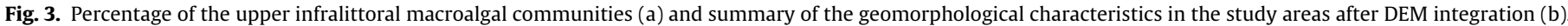
Values are shown as percentages.

Table 4

Poisson Regression Model results-significant variables, percentage of explained deviance and predictive error.

\begin{tabular}{|c|c|c|c|c|c|c|c|}
\hline Island & Aspect & Coast Elevation & Landform & Coast Slope & Coastline Slope & \% Explained Dev. & Predictive Error \\
\hline Zannone & $\bullet$ & & $\bullet$ & & • & 31.76 & 0.417 \\
\hline Ponza & $\bullet$ & & $\bullet$ & & • & 28.14 & 0.346 \\
\hline Ventotene & $\bullet$ & & $\bullet$ & & $\bullet$ & 58.70 & 0.266 \\
\hline Giglio & $\bullet$ & & $\bullet$ & $\bullet$ & - & 20.16 & 0.712 \\
\hline
\end{tabular}

of low sunny rocks completely covered by Cystoseira populations lying opposite high vertical cliffs lined by Corallinales.

All the modeling results used in this study reliably demonstrate that the only variable that is always relevant to the establishment of Cystoseira on the coastline slope is the inclination of the cliffs at the infralittoral fringe. Even when the landform plays a statistically significant role, as on Zannone and Ventotene, the coastline slope exerts a positive influence on the occurrence of Cystoseira. Further- 


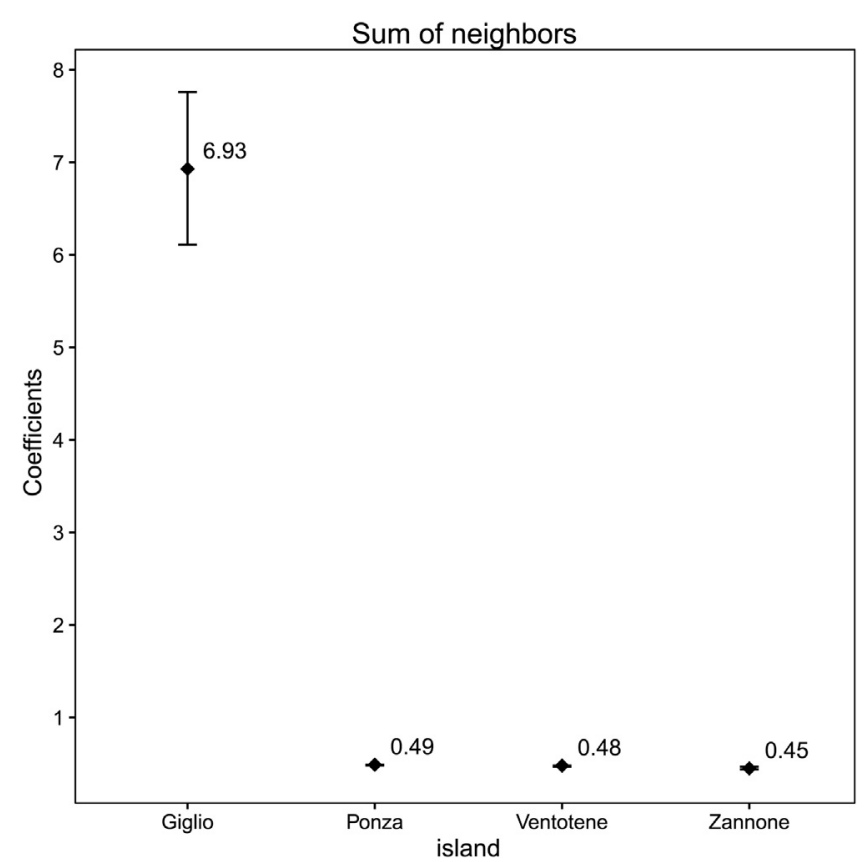

Fig. 4. Coefficients of the sum of neighbors variable in the autologistic models estimated in the study area. Segments represent $95 \%$ confidence limits.

more, when the Cystoseira clusters (the sum of neighbors) were analyzed by means of the Poisson regression model, the coastline slope was still significant, with the horizontal and sub-vertical categories of slopes exerting a positive effect on the cluster size. Nikolić et al. (2013), who performed descriptive analyses, had already suggested that the most important geomorphological factor affecting the distribution of the macroalgal communities along the coast of Croatia was the coastline slope. The coastline surveyed by those authors was "predominantly a low coast type with horizontal to sub-vertical slopes" (Nikolić et al., 2013). The present analysis proved, in a statistically rigorous way, that the same geomorphological factor conditions the distribution of these communities in sites where high coast dominates. Therefore, the establishment of Cystoseira on pristine coasts is influenced by the inclination of the cliffs at the infralittoral fringe to a greater extent than by the type of coast (high or low). This is particularly evident when Giglio and Zannone are compared. The dominance of horizontal to sub-vertical coastline slopes on Giglio favors a very extensive presence of Cystoseira belts (74\%), whereas the dominance of vertical coastline slopes on Zannone favors the establishment of Corallinales communities and restricts the extension of Cystoseira belts. A less extreme situation is found on Ventotene and Ponza, where the presence of a large percentage of horizontal coastline slopes (44\% and 35\%, respectively) allows a higher presence of Cystoseira than on Zannone. This percentage is not, however, high enough to allow the CARLIT index to assign a high ecological status to the waters of these two islands. This underestimation is due to the fact that CARLIT index does not take into account the inclination of the slope at the infralittoral fringe. An adjustment of this formula would entail calibrating the data from both the reference sites and the Pontine islands. As information on the steepness of the slopes in the reference sites is not available, and in order to avoid multiplying the number reference sites, we propose an empirical adjustment of the $\mathrm{EQV}$ on the basis of the findings of this study. Since we observed an average reduction of $35 \%$ (ranging from $27 \%$ on Ventotene to $47 \%$ on Zannone) in the Cystoseira communities on coasts where the percentage of vertical coastline slopes is above $40 \%$, we suggest that the EQV calculated on these coasts be increased by $35 \%$. Indeed, if this increase were applied to the three Pontine islands, their ecological status would rise to "high" (ratios: 0.77, 0.79, 0.82 for Zannone, Ponza and Ventotene, respectively), thereby rendering the CARLIT index reliable even on coasts with steep slopes. This simple empirical adjustment would obviate the need to modify the procedure or to hastily multiply the number of references sites, at least until further studies conducted on the CARLIT index in other Mediterranean areas, which the promoters of this protocol them-

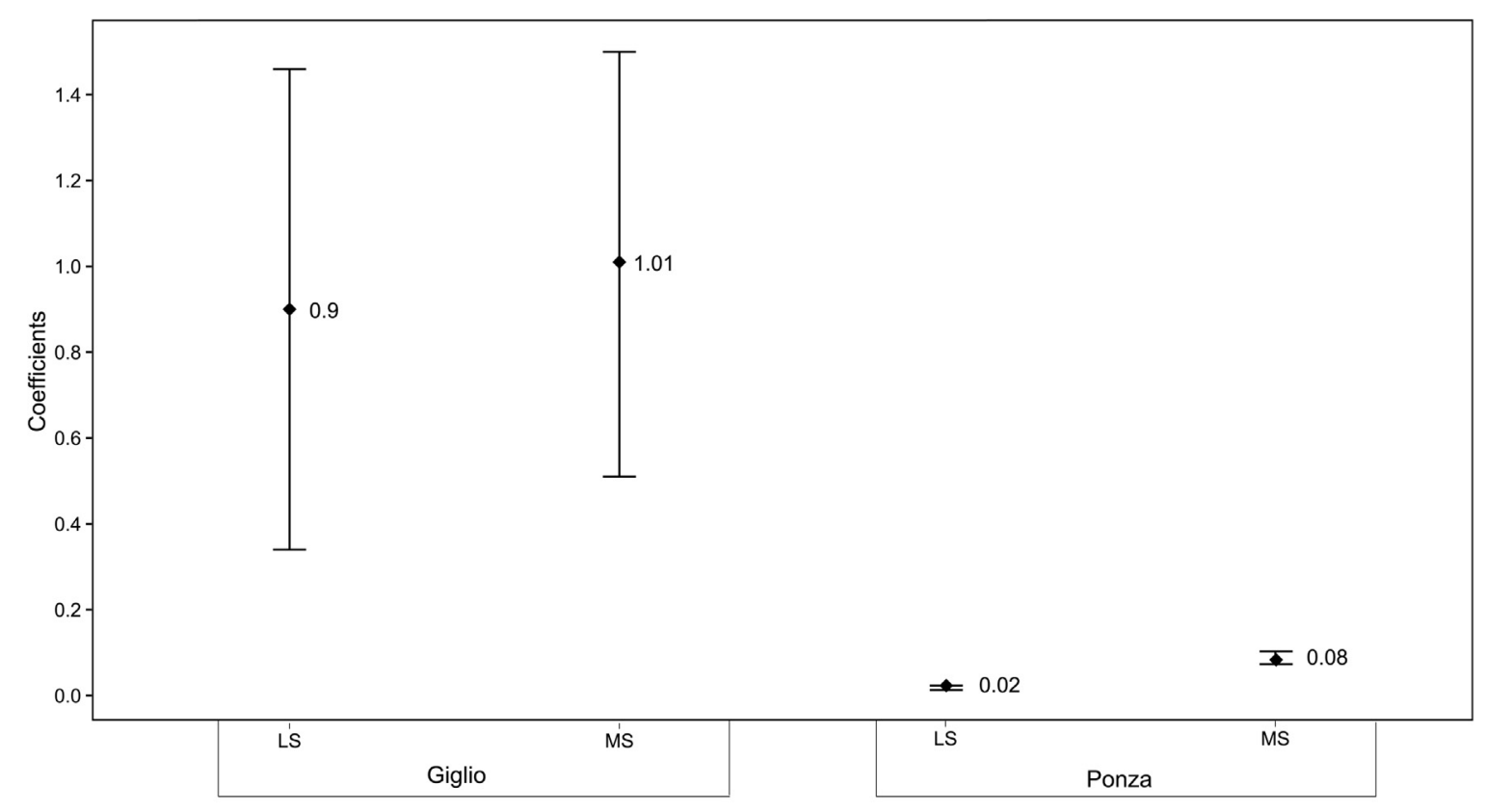

Coastline slope

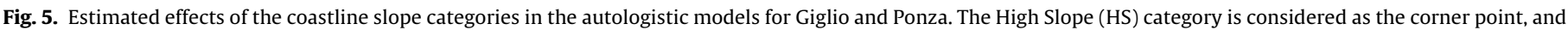

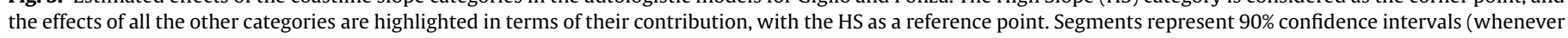
the interval includes the zero value, the effects are not significant). 


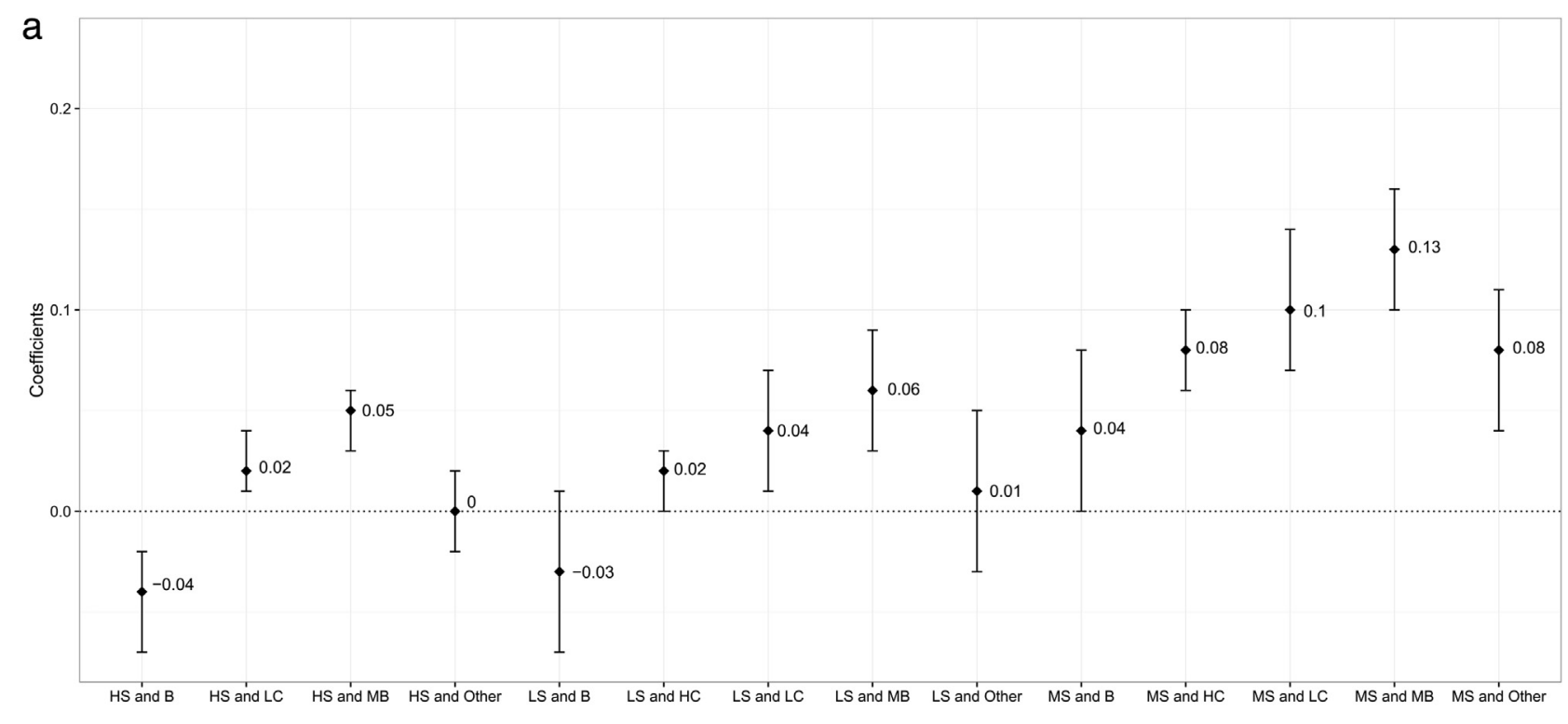

Coastline slope and landform

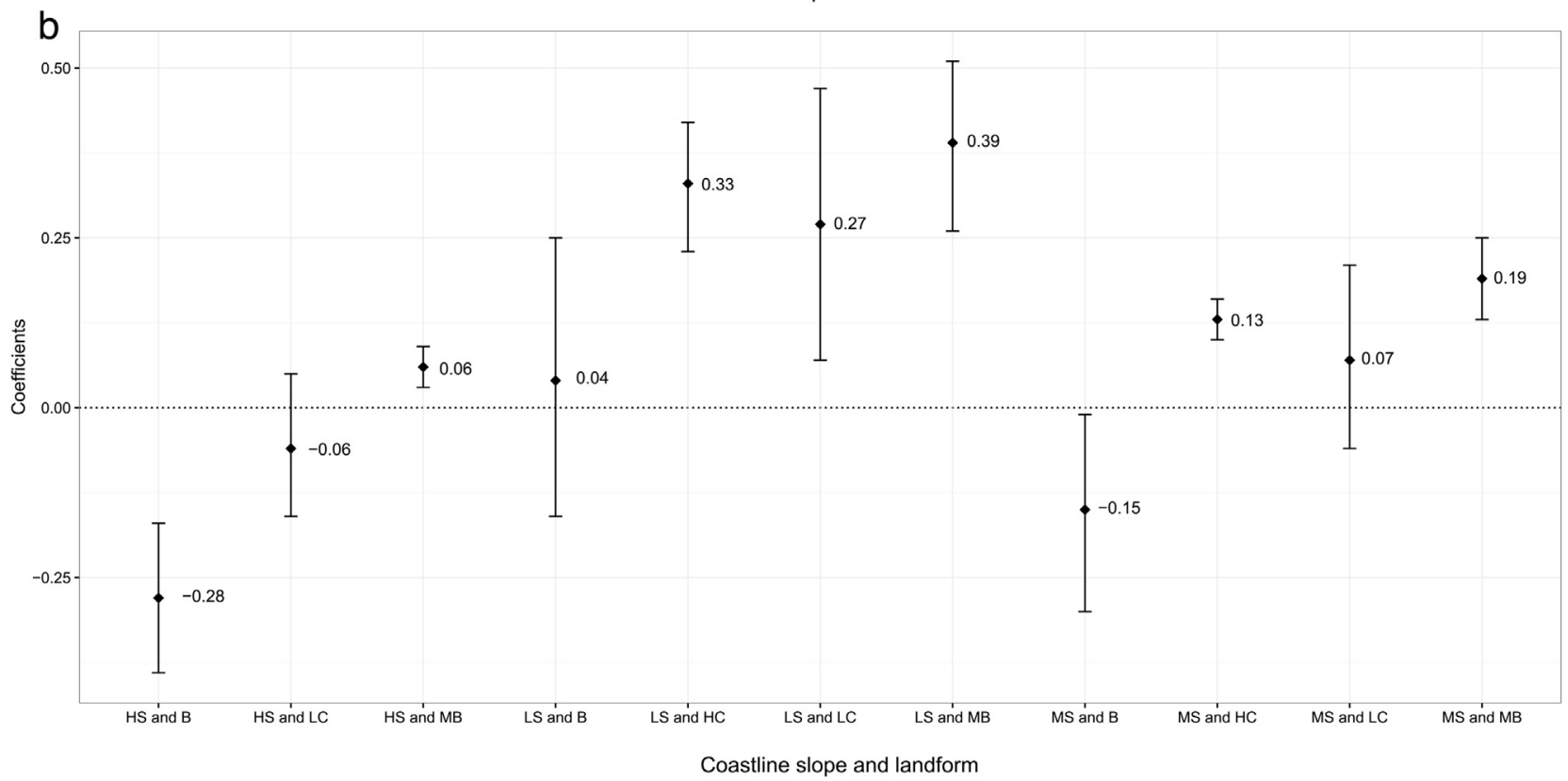

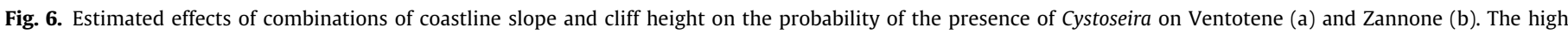

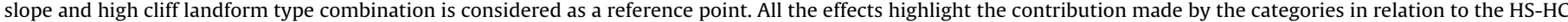
combination. Segments represent $90 \%$ confidence intervals (whenever the interval includes the zero value, the effects are not significant).

selves encourage (Ballesteros et al., 2007), shed further light on this issue.

\section{Acknowledgments}

The authors wish to thank Simona Sirago for her help in collecting the data, Edoardo Scepi for his contribution to an earlier version of this work, and Franca Melis and Domenico Melis for their kind help during the Giglio survey. The authors are also very grateful to the two anonymous referees for their useful comments.

\section{References}

Arevalo, R., Pinedo, S., Ballesteros, E., 2007. Changes in the composition and structure of Mediterranean rocky shore communities following a gradient of nutrient enrichment: descriptive study and test of proposed methods to assess water quality regarding macroalgae. Mar. Pollut. Bull. 55, 104-113.
Asnaghi, V., Chiantore, M., Bertolotto, R.-M., Parravicini, V., Cattaneo-Vietti, R., Gaino, F., Moretto, P., Privitera, D., Mangialajo, L., 2009. Implementation of the European Water Framework Directive: Natural variability associated with the CARLIT method on the rocky shores of the Ligurian Sea (Italy). Mar. Ecol. 30, 505-513.

Ballesteros, E., Torras, X., Pinedo, S., García, M., Mangialajo, L., De Torres, M., 2007. A new methodology based on littoral community cartography dominated by macroalgae for the implementation of the European Water Framework Directive. Mar. Pollut. Bull. 55 (1), 172-180.

Bermejo, R., De La Fuente, G., Vergara, J.J., Hernandez, I., 2013. Application of the CARLIT index along a biogeographical gradient in the Alboran Sea (European Coast). Mar. Pollut. Bull. 72, 107-118.

Bermejo, R., Mangialajo, L., Vergara, J.J., Hernandez, I., 2014. Comparison of two indices based on macrophyte assemblages to assess the ecological status of coastal waters in the transition zone between the Atlantic and Mediterranean eco-regions. J. Appl. Phycol. 26, 1899-1909.

Besag, J., 1975. Statistical analysis of non-lattice data. The Statistician, 179-195.

Blanfuné, A., Markovic, L., Thibaut, T., 2011. Assessment of CARLIT methodology in the Mediterranean rocky water bodies. In: Programme and Abstracts, Fifth European Phycological Congress EPC5, Rhodes, Greece, 04-09 September (173 pp.). 
Blanfuné, A., Boudouresque, C.F., Verlaque, M., Beqiraj, S., Kashta, L., Nasto, I., Ruci, S., Thibaut, T., 2016. Response of rocky shore communities to anthropogenic pressures in Albania (Mediterranean Sea): Ecological status assessment through the CARLIT method. Mar. Pollut. Bull. 109, 409-418.

Blanfuné, A., Thibaut, T., Boudouresque, C.F., Macic, V., Markovic, L., Palomba, L., Verlaque, M., Boissery, P., 2017. The CARLIT method for the assessment of the ecological quality of European Mediterranean waters relevance, robustness and possible improvements. Ecol. Indic. 72, 249-259.

Cameron, A.C., Trivedi, P.K., 2013. Regression Analysis of Count Data. Cambridge University Press.

Cavallo, M., Torras, X., Mascaró, O., Ballesteros, E., 2016. 2016 Effect of temporal and spatial variability on the classification of the Ecological quality status using the CARLIT Index. Mar. Pollut. Bull. 102, 122-127.

Cressie, N.A.C., 2015. Statistics for Spatial Data Revised Edition. Wiley Classic Library.

ESRI, 2011. ArcGIS Desktop: Release 10. Redlands, CA: Environmental Systems Research Institute.

Fu, R., Thurman, A.L., Chu, T., Steen-Adams, M.M., Zhu, J., 2013. On estimation and selection of autologistic regression models via penalized pseudolikelihood. J. Agric. Biol. Environ. Stat. 18, 429-449.

Guala, I., Torras, X., Simeone, S., Ballesteros, E. 2010. Valutazione della qualità ecologica delle acque costiere nell'Area Marina Protetta Penisola del Sinis Isola de Mal di Ventre (Sardegna occidentale) secondo il metodo C̈ARLIT: In: 32 Atti S.It.E. XVIII Congresso Nazionale, Parma 1-3 settembre 2008 (G. Giordani, V. Rossi \& P. Viaroli). pp. 61-67. Società Italiana di Ecologia.

Jona Lasinio, G., Tullio, M.A., Abdelahad, N., Scepi, E. Sirago, S., Pollice, A. 2011. Statistical calibration of the Carlit index in the Pontine Island of Zannone. Spatial Data Methods for Environmental and Ecological Processes, 2nd edition - Proceedings, 4 pp.

Mangialajo, L., Ruggieri, N., Asnaghi, V., Chiantore, M., Povero, P., Cattaneo-Vietti, R., 2007. Ecological status in the Ligurian Sea: the effect of coastline urbanisation and the importance of proper reference sites. Mar. Pollut. Bull. 55, 30-41.

Mangialajo, L., Chiantore, C., Cattaneo-Vietti, R., 2008a. Loss of fucoid algae along a gradient of urbanization and relationships with the structure of benthic assemblages. Mar. Ecol. Prog. Ser. 358, 63-74.
Mangialajo, L., Sartoni, G., Giovanardi, F., 2008b. Quaderno Metodologico Sull'elemento Biologico Macroalghe E Sul Calcolo Dello Stato Ecologico Secondo La Metodologia CARLIT. ISPRA Istituto Superiore per la protezione e la Ricerca Ambientale (105 pp).

Nikolić, V., Žuljević, A., Mangialajo, L., Antolić, B., Kušpilić, G., Ballesteros, E., 2013. Cartography of littoral rocky-shore communities (CARLIT) as a tool for ecological quality assessment of coastal waters in the Eastern Adriatic Sea. Ecol. Indic. 34, 87-93.

Pinedo, S., García, M., Satta, M.P., Torres de, M., Ballesteros, E., 2007. Rocky-shore communities as indicators of water quality: a case study in the Northwestern Mediterranean. Mar. Pollut. Bull. 55, 126-135.

Sfriso, A., Facca, C., 2011. Macrophytes in the anthropic constructons of the Venice littorals and their ecological assessment by an integration of the CARLIT index. Ecol. Indic. 11, 772-781.

Tarquini, S., Isola, I., Favalli, M., Mazzarini, F., Bisson, M., Pareschi, M.T., Boschi, E., 2007. TINITALY/01: a new triangular irregular network of Italy. Ann. Geophys. 50, 407-425.

Tarquini, S., Vinci, S., Favalli, M., Doumaz, F., Fornaciai, A., Nannipieri, L., 2012. Release of a 10-m-resolution DEM for the Italian territory: comparison with global-coverage DEMs and anaglyph-mode exploration via the web. Comput. Geosci. 38, 168-170, http://dx.doi.org/10.1016/j.cageo.2011.04.018.

Thibaut, T., Pinedo, S., Torras, X., Ballesteros, E., 2005. Long-term decline of the populations of Fucales (Cystoseira spp. and Sargassum spp.) in the Albères coast (France, North-western Mediterranean). Mar. Pollut. Bull. 50, 1472-1489.

Torras, X., Pinedo, S., Garcia, M., Weitzmann, B., Ballesteros, E., 2016.

Environmental quality of Catalan coastal waters based on macroalgae: the interannual variability of CARLIT index and its ability to detect changes in anthropogenic pressures over time. In: Munné, A., Ginebreda, A., Prat, N. (Eds.), Experiences from Ground, Coastal and Transitional Water Quality Monitoring: The EU Water Framework Directive Implementation in the Catalan River Basin District (Part II): 183-199. The Handbook of Environmental Chemistry, 43. Springer International Publishing, Switzerland. 